\title{
Inferential consequences of modeling rather than measuring snow accumulation in studies of animal ecology
}

\author{
Author: A. Brennan, P.C. Cross, M. Higgs, J.P. \\ Beckmann, R.W. Klaver, B. M. Scurlock, \& S. Creel
}

Copyright by the Ecological Society of America "This is the final version of record of an article that originally appeared in Ecological Applications in April 2013.”

Brennan A, Cross PC, Higgs M, Beckmann JP, Klaver RW, Scurlock BM \& Creel S 2013 Inferential consequences of modeling rather than measuring snow accumulation in studies of animal ecology. Ecological Applications, 23:643-653.

http://dx.doi.org/10.1890/12-0959.1

Made available through Montana State University's $\underline{\text { ScholarWorks }}$ 


\title{
Inferential consequences of modeling rather than measuring snow accumulation in studies of animal ecology
}

\author{
Angela Brennan,,${ }^{1,7}$ Paul C. Cross, ${ }^{2}$ Megan Higgs, ${ }^{3}$ Jon P. Beckmann, ${ }^{4}$ Robert W. Klaver, ${ }^{5}$ \\ Brandon M. Scurlock, ${ }^{6}$ And Scott Creet $^{1}$ \\ ${ }^{1}$ Department of Ecology, 310 Lewis Hall, Montana State University, Bozeman, Montana 59717 USA \\ ${ }^{2}$ U.S. Geological Survey, Northern Rocky Mountain Science Center, 2327 University Way, Bozeman, Montana 59715 USA \\ ${ }^{3}$ Department of Mathematical Sciences, 2-214 Wilson Hall, Montana State University, Bozeman, Montana 59717 USA \\ ${ }^{4}$ Wildlife Conservation Society, North America Program, 301 North Willson Avenue, Bozeman, Montana 59715 USA \\ ${ }^{5}$ U.S. Geological Survey, Iowa Cooperative Fish and Wildlife Unit, Science Hall II, Iowa State University, Ames, Iowa 50011 USA \\ ${ }^{6}$ Wyoming Game and Fish Department, 423 East Mill Street, Pinedale, Wyoming 82941 USA
}

\begin{abstract}
It is increasingly common for studies of animal ecology to use model-based predictions of environmental variables as explanatory or predictor variables, even though model prediction uncertainty is typically unknown. To demonstrate the potential for misleading inferences when model predictions with error are used in place of direct measurements, we compared snow water equivalent (SWE) and snow depth as predicted by the Snow Data Assimilation System (SNODAS) to field measurements of SWE and snow depth. We examined locations on elk (Cervus canadensis) winter ranges in western Wyoming, because modeled data such as SNODAS output are often used for inferences on elk ecology. Overall, SNODAS predictions tended to overestimate field measurements, prediction uncertainty was high, and the difference between SNODAS predictions and field measurements was greater in snow shadows for both snow variables compared to non-snow shadow areas. We used a simple simulation of snow effects on the probability of an elk being killed by a predator to show that, if SNODAS prediction uncertainty was ignored, we might have mistakenly concluded that SWE was not an important factor in where elk were killed in predatory attacks during the winter. In this simulation, we were interested in the effects of snow at finer scales $\left(<1 \mathrm{~km}^{2}\right)$ than the resolution of SNODAS. If bias were to decrease when SNODAS predictions are averaged over coarser scales, SNODAS would be applicable to population-level ecology studies. In our study, however, averaging predictions over moderate to broad spatial scales $\left(9-2200 \mathrm{~km}^{2}\right)$ did not reduce the differences between SNODAS predictions and field measurements. This study highlights the need to carefully evaluate two issues when using model output as an explanatory variable in subsequent analysis: (1) the model's resolution relative to the scale of the ecological question of interest and (2) the implications of prediction uncertainty on inferences when using model predictions as explanatory or predictor variables.
\end{abstract}

Key words: Cervus canadensis; climate variables; elk; prediction uncertainty; SNODAS; snow shadow; snowpack model; winter range.

\section{INTRODUCTION}

Statistical and mathematical models are often used to predict environmental variables where and when direct measurements are not collected (e.g., PRISM, Daymet, and WorldClim climate variables). These models may vary in complexity, extent, and spatial and temporal resolution (see Watson et al. [2006] for comparison of snowpack models), but they commonly rely on interpolation among sparsely distributed direct measurements (Daly 2006, Fuentes et al. 2006) or downscaling to reach finer resolutions (Wilby and Wigley 1997, Wilby et al. 2004, Tabor and Williams 2010, Fordham et al. 2011,

Manuscript received 9 June 2012; revised 28 September 2012; accepted 18 October 2012. Corresponding Editor: D. S. Schimel.

${ }^{7}$ E-mail: angie_brennan@hotmail.com
Littell et al. 2011). Model predictions may represent broad trends with little bias when averaged over large areas or time frames, while prediction error increases at finer scales (Daly 2006). At any scale, prediction uncertainty is rarely quantified or accounted for in the analysis or conclusions of ecological studies that use model predictions as explanatory or predictor variables. Given the number of such studies using model predictions in place of direct measurements $(\geq 9$ articles in Ecology and 19 in Ecological Applications from January 2011 to February 2012 [e.g., Cord and Rödder 2011, Erb et al. 2011]), it is important to understand the inferential consequences of treating these predictions as if they were directly measured data without error. We used predictions of snow accumulation generated from the Snow Data Assimilation System (SNODAS) to demonstrate potential levels of model prediction error at scales 
relevant to wildlife ecology, and to examine the practical effects of using model predictions in place of direct measurements in a typical wildlife application (SNODAS data available online) ${ }^{8}$

Snow accumulation is strongly associated with the behavior and ecology of animals in cold climates (Nelson and Mech 1986, Hobbs 1989, Hupp and Braun 1989, Brodie and Post 2010, Beckmann et al. 2012), and therefore snowpack models such as SNODAS may appeal to wildlife researchers and managers who require snow data at times or places where field measurements cannot be collected (e.g., daily measurements at multiple remote locations). Snow variables recorded at fine spatial (e.g., $\leq 0.05 \mathrm{~km}^{2}$ ) and moderate to fine temporal scales (e.g., once every other week, or more often) can be important for understanding individual animal behavior (Christianson and Creel 2008), as snow can reduce access to forage patches (Craighead et al. 1973, Bruggeman 2006), decrease ability to escape predators, increase predator kill rate (Nelson and Mech 1986, Huggard 1993), change diet composition (Huggard 1993, Christianson and Creel 2007), or increase energy expenditure for thermoregulation, travel, and search for food (Parker et al. 1984, Telfer and Kelsall 1984). Cumulatively, these effects on individuals can result in population-level responses to snow accumulation, such as changes in recruitment, survival, or distribution. Analysis of these population-level effects typically requires data on snow variables collected at broad spatial (e.g., $\geq 100 \mathrm{~km}^{2}$ for large mammals) and temporal scales (e.g., once each year or more; Garrott et al. 2003).

SNODAS has the potential for wide application to animal ecology studies because it predicts snow water equivalent (SWE) and snow depth at relatively fine spatial and temporal resolutions (e.g., $1 \mathrm{~km}^{2}$, daily) and broad extents (e.g., contiguous United States), from 2003 to the present. However, SNODAS was developed by the National Operational Hydrologic Remote Sensing Center (NOHRSC) to support basin-scale hydrologic models, not wildlife research. SNODAS predictions are generated from ingested Numerical Weather Prediction (NWP) model estimates of air temperature, relative humidity, wind speed, and precipitation that are downscaled from a $13-\mathrm{km}^{2}$ to a $1-\mathrm{km}^{2}$ resolution (Barrett 2003, Carroll et al. 2006). Multisensor snow data are then assimilated into the model in order to update model output. These data include SWE and snow depth provided by the National Weather Service (e.g., weather stations and cooperatives), federal and state agencies (e.g., Natural Resources Conservation Service's [NRCS] Snow Telemetry [SNOTEL] stations and snow course sites), and regional mesonets (i.e., network of environmental monitoring stations); SWE obtained via the NOHRSC-operated airborne

${ }^{8}$ http://nsidc.org/data/g02158.html snow survey program; and satellite remote sensing data used to capture the extent of snow cover (i.e., snow presence and absence). SNODAS also integrates digital elevation map (DEM)-derived slope and aspect, remotely sensed forest cover and type, and soils data (Barrett 2003, Carroll et al. 2006).

SNODAS relies on relatively few, sparsely distributed, direct field observations of snow to update model output, and therefore prediction uncertainty could be high at fine spatial scales. This problem is not unique to SNODAS, and prediction uncertainty has been discussed frequently in the contexts of other snowpack and rainfall-runoff models (e.g., Chaplot et al. 2005, Franz et al. 2010, Kuczera et al. 2010, Renard et al. 2011), as well as downscaled global circulation models (GCMs; e.g., Wilby 1997, Wilby and Wigley 1997, Wilby et al. 2004, Tabor and Williams 2010, Fordham et al. 2011, Littell et al. 2011). The effects of prediction uncertainty have also been explored, but generally in the contexts of using precipitation models to drive biogeochemical simulations (Fuentes et al. 2006) or using GCM predictions of temperature and precipitation to project natural resource dynamics (Littell et al. 2011) or species distributions under future climate scenarios (Tabor and Williams 2010, Fordham et al. 2011). Prediction uncertainty has not been addressed, however, in animal ecology studies that use model predictions of snow accumulation such as SNODAS output as explanatory variables. To examine the consequences of this problem in a wildlife ecology setting, we compared SNODASpredicted SWE and snow depth to field measurements collected from elk winter ranges in western Wyoming to (1) measure SNODAS SWE and snow depth prediction bias and uncertainty, (2) examine the potential consequences of SNODAS prediction uncertainty for inferences on the relationship between snow and animal ecology (using a simulation in elk ecology), and (3) determine whether SNODAS prediction bias decreases at broad spatial scales applicable to population-level studies of large mammals. Our goal was to highlight potential issues that may arise from using model predictions of snow in place of direct measurements in a typical wildlife application, not to validate SNODAS as a metric of snow for other purposes (e.g., hydrologic forecasting).

\section{Methods \\ Study area}

Across our study area, which covered $15000 \mathrm{~km}^{2}$ in western Wyoming (Fig. 1), we compared SNODAS predicted SWE and snow depth to field measurements collected during the months of January through March 2009 and 2010 at sites where elk are supplementally fed in winter (i.e., feedgrounds) and where elk winter off feedgrounds (i.e., native winter range). These study sites were located along the western foothills of the Wind River Range, the Wyoming Range and its eastern foothills, the uplands of the Upper Green River Basin, 


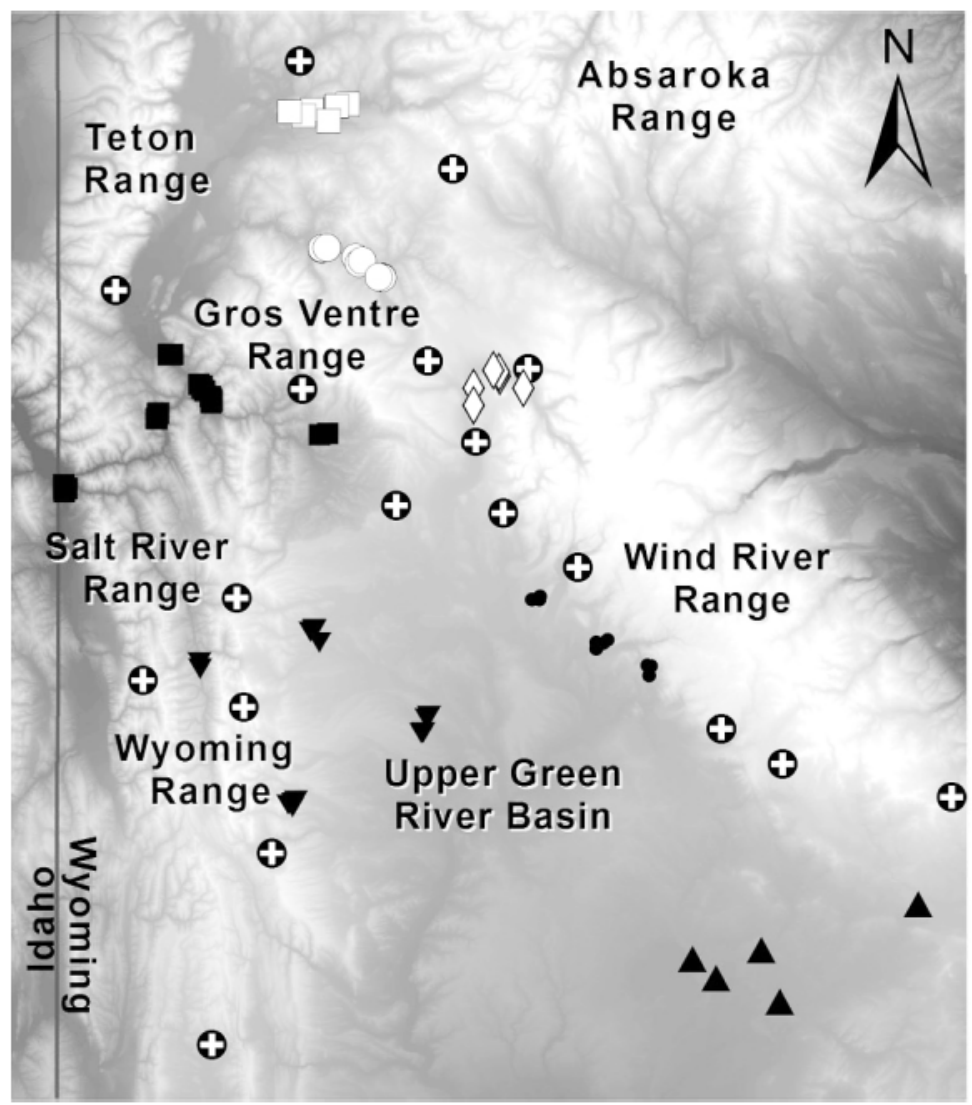

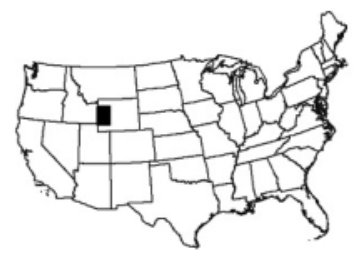

Region 1

Region 2

- Region 3

$\diamond$ Region 4

- Region 5

$\boldsymbol{\nabla}$ Region 6

- Region 7

† SNotel stations
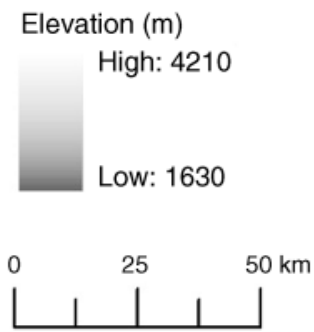

FIG. 1. Map of study area, showing snow sampling transects within seven general regions, the 18 Natural Resources Conservation Service's Snow Telemetry (SNOTEL) stations nearest to transect locations, Wyoming cities (Jackson, Pinedale, and Dubois), elevation (m), and relevant mountain ranges. White-filled region symbols are snow shadow regions.

the northern foothills of the Salt River Range, and the northern, southern, and western foothills and valleys of the Gros Ventre Range (Fig. 1). Site elevations ranged from roughly 1700 to $2750 \mathrm{~m}$ and the topography ranged from high mountain valleys and varying grades of mountain slopes, to open, rolling mountain foothills. Vegetation in the mountain valleys and foothills was characteristic of Rocky Mountain montane, subalpine, or riparian habitats, which includes closed conifer forests (Pinus spp., Picea spp., Abies lasiocarpa), willow (Salix spp.), aspen (Populus tremuloides), grass-forb/ herb meadows, and shrubs (Artemisia spp., Amelanchier alnifolia). High mountain slopes were dominated by rock and talus. Lowlands were dominated by sagebrush (Artemisia spp.), saltbrush (Atriplex spp.), greasewood (Sarcobatus vermiculatus), herbaceous species, and irrigated hay meadows. Approximately 22000 elk winter on feedgrounds and another 4000 winter on native winter range in the study area (Wyoming Game and Fish Department 2006, Maichak et al. 2009).

The study area has long, often severe, winters generally lasting from October through May, although it is not unusual for snow accumulation to begin in September and continue through mid-June. During the winters of 2008-2009 and 2009-2010 (i.e., when snow accumulation $>0$ ), the 18 SNOTEL stations in our study area (Fig. 1) recorded a mean SWE of 29 and $21 \mathrm{~cm}$, and mean snow depth of 101 and $90 \mathrm{~cm}$, respectively. Parts of the Gros Ventre Range directly east of the Tetons are located in snow shadows (Hobbs et al. 2003), which are areas on the leeward side of mountain ranges that receive less snow than typical areas of comparable elevation.

\section{Sampling design}

For our study sites, we selected 16 feedgrounds and three native winter ranges to cover the range of habitat, elevation, and topography used by wintering elk in western Wyoming. We used SNODAS grid cells $\left(1-\mathrm{km}^{2}\right.$ pixels) as our sampling units, simply to pair field measurements with SNODAS predictions (not to validate SNODAS at the pixel scale). On the feedgrounds, we randomly selected two SNODAS pixels within a circular area defined by a $2 \mathrm{~km}$ radius from the center of each feedground. For the native winter ranges, we used areas delineated as elk winter range by the Wyoming Game and Fish Department and randomly 
selected five to seven SNODAS pixels within each of those areas.

Within each selected SNODAS pixel, we measured SWE and snow depth along one 150-m transect with random starting location and azimuth, though adjustments were made to the azimuth when necessary to ensure transects remained in the original pixel. Along each transect, we collected five snow cores (using a Mt. Rose Federal snow sampler; Rickly Hydrological Company, Columbus, Ohio, USA) $30 \mathrm{~m}$ apart to measure SWE and snow depth, as well as four additional snow depth measurements $15 \mathrm{~m}$ from each snow core location in each of the cardinal directions. We estimated mean transect values for both snow variables, but to improve precision of mean transect estimates of SWE we used the ratio of SWE to snow depth from snow cores to estimate SWE where only snow depth was measured (Rovansek et al. 1993). Hereafter, we refer to mean transect values as field estimates of SWE or snow depth.

We randomly selected pixels and sampled new transects each winter (in 2009 and 2010) at 11 of the feedgrounds. At the remaining five feedgrounds and three winter ranges, we sampled transects only in 2010 . Also in 2010, we randomly selected an additional eight pixels across four of the feedgrounds (two pixels per feedground) that had minimal constraints to access (due to elk management practices or private land restrictions) and repeatedly sampled one transect within each of those pixels at sampling intervals of 15-30 days. We used these repeated samples to assess whether or not SNODAS prediction accuracy changed throughout a winter.

The total area covered by each transect was $4500 \mathrm{~m}^{2}$ ( $150 \mathrm{~m}$ in length, $30 \mathrm{~m}$ in width), which is obviously a small fraction of a $1-\mathrm{km}^{2}$ SNODAS pixel. However, our intention was not to validate SNODAS at the pixel scale. Rather, the goal was to quantify how well SNODAS predicts snow at the transect scale in areas used by wintering elk and to measure snow as it relates to elk ecology. Therefore, we used sampling methods typical of studies of snow effects on ungulate ecology (Hoskinson and Tester 1980, Sweeney and Sweeney 1984, Anderson et al. 2005, Fortin et al. 2009), which are also similar to those used by the NRCS to measure snow accumulation at snow course sites. Since field estimates were obtained at a much finer scale than the SNODAS resolution, however, differences between SNODAS predictions and field estimates may be attributable to how well SNODAS estimates the average snow depth and SWE for a pixel, as well as the amount of variation within that pixel.

\section{AnAlysis}

\section{SNODAS accuracy and precision}

As a result of our sampling design, our field estimates were clustered by site (19 total study sites: 16 feedgrounds plus 3 native winter ranges). Therefore, we conducted all analyses using linear mixed-effects models with site as the random effect (i.e., allowing the intercept to vary by site) to account for the correlation among field estimates from the same site. We used the $R$ environment for statistical computation ( $R$ Code Development Team 2011) with the package lme4 (available online). ${ }^{9}$ We examined the assumptions of linear regression, and all were reasonably met.

We calculated SNODAS bias, which we defined as the difference between SNODAS predictions and field estimates. We also aggregated the study sites into seven regions (Fig. 1). We defined region post hoc as either a discrete elk native winter range or a set of feedgrounds closest to one another. Using linear models of SNODAS bias (response variable) on region (explanatory variable), we estimated the mean SNODAS bias and $95 \%$ confidence intervals (CIs) by region for both snow variables.

Retrospectively, we observed less snow on average at transects located in snow shadows of the Teton and Gros Ventre Ranges compared to other transect locations, even though transect elevations tended to be higher in snow shadows (Appendix A: Fig. A1). We did not anticipate that SNODAS bias would be greater in snow shadows, but differences were revealed between these and other regions. To demonstrate the magnitude of the prediction bias in snow shadows, we compared the estimated mean SNODAS bias and $95 \%$ CIs for both snow variables in snow shadows to other regions. Our goal for this comparison was not to suggest that SNODAS bias is only a concern in snow shadows, but rather to highlight the effect of potentially unaccounted for local-scale atmosphere or land surface properties on prediction bias. Other study sites may be impacted by different physical processes potentially not captured by SNODAS.

We examined the linear relationship between SNODAS predictions (predictor variable) and field estimates (response variable) of SWE or snow depth and compared the estimated intercept, slope, and $95 \%$ CIs to a 1:1 relationship (i.e., slope $=1$, intercept $=0$ ). We repeated this analysis without snow shadow data to determine the effect of snow shadows on regression bias. Because the estimated linear relationship between SNODAS predictions and field estimates does not account for the scatter around the regression line, we quantified the effect of bias and variance on future field estimates predicted from new SNODAS values using 95\% prediction intervals (PIs).

Finally, we examined whether or not SNODAS predictions matched field estimates more closely earlier in the winter when there may be less snow on the ground, compared to later in the winter. We plotted SNODAS bias for SWE over time for transects measured repeatedly in 2010 to assess evidence for a time trend in SNODAS bias.

9 http://CRAN.R-project.org/package=lme4 


\section{Testing snow effects in an ecological model}

To demonstrate the potential consequences of using model predictions in place of field measurements, we prepared a hypothetical example relating SNODASpredicted SWE to the (relative) probability of an elk being killed by a predator. This is based on a comparison of SWE at kill sites relative to SWE at "available" sites, which are generally defined as random sites within the nearby area (Hebblewhite et al. 2005). We used SWE because it incorporates snow depth and density, and has been identified as the best predictor of ungulate responses to snow in our study area (Farnes et al. 1999). Elk generally avoid areas that exceed $15 \mathrm{~cm}$ SWE, and are known to more commonly use winter ranges with less than $7 \mathrm{~cm}$ SWE (Farnes and Romme 1993). Our field estimates of SWE ranged roughly from 0 to $20 \mathrm{~cm}$ and SNODAS predictions ranged from 2 to $35 \mathrm{~cm}$, which not only covers typical levels of SWE on an elk winter range, but also spans the levels of SWE detected in studies of snow effects on probability of an elk kill (Becker 2008).

We simulated random binary outcomes representing kill or no kill from a binomial distribution with probabilities obtained from a logistic regression model with our field estimates of SWE as the explanatory variable, an intercept $=-0.9$, and slope $=0.11$. These hypothetical parameters were not empirically estimated, but represent reasonable approximations of how elk kills may be related to snowpack, while holding other variables constant. We fit two logistic regression models to our simulated binary response variable. In the first model, we used field estimates of SWE (same data used to generate the response variable) as the explanatory variable, and in the second we used SNODAS-predicted SWE as the explanatory variable to represent a situation where an ecologist may use SNODAS predictions in place of direct observations. We conducted the simulation and analyses in $\mathrm{R}$.

\section{SNODAS prediction at multiple spatial scales}

Our sampling was not designed to test SNODAS accuracy at scales coarser than the transect. However, if SNODAS did poorly at predicting SWE and snow depth at the transect level, we hypothesized that predictions might improve at coarser spatial scales applicable to population-level studies of large mammals. Therefore, we examined SNODAS predictions at the feedground and region scales ranging from 9 to $2200 \mathrm{~km}^{2}$. At the feedground scale, we averaged all SNODAS pixels falling at least partially within a $2 \mathrm{~km}$ radius around the center of each feedground on dates field sampling occurred. The number of pixels included was not identical among feedgrounds, resulting in areas ranging from 9 to $14 \mathrm{~km}^{2}$. For region-scale calculations, we generated a circular area having a diameter equal to the greatest distance between sample locations within a region and a centroid equal to the midpoint between those sample locations. The resulting region-scale areas ranged from 150 to $2200 \mathrm{~km}^{2}$.

Within each feedground or region area, we averaged only those SNODAS pixel values occurring within the elevation range of elk feedgrounds and native winter ranges in the study area $(1700-2750 \mathrm{~m})$. Feedground and region-scale field estimates were the average of all field measurements along all transects (SWE or snow depth) contained in each feedground or region, respectively. The number of field measurements of SWE ranged from 10 to 25 per feedground and from 25 to 100 per region. For snow depth, the number of field measurements ranged from 50 to 125 per feedground and from 125 to 500 per region.

We calculated SNODAS bias for both snow variables as the difference between the averaged SNODAS predictions and the averaged field measurements at the feedground or region scale. We use the term "SNODAS bias" because it is used throughout this document to describe the differences between SNODAS predictions and field estimates, but we acknowledge that differences calculated at the region scale may be due, in part, to the assignment of region after sampling occurred, or to the lack of random samples outside study sites (resulting in biased field estimates at the region scale). However, we argue that our field estimates are a better representation of the average SWE and snow depth across potential elk winter range in the study area than SNOTEL data, which are used to update SNODAS predictions and are frequently used in elk ecology studies to estimate snow conditions at spatial scales similar to our feedground and region scales (e.g., Singer et al. 1997, Taper and Gogan 2002). Because SNOTEL stations are sparsely distributed, few stations are used to depict snow conditions at those scales, and they are typically located at elevations higher than the winter ranges of large herbivores.

We quantified the mean SNODAS bias at the transect scale using a linear random effects model (intercept only) with site (19 total study sites) as the random effect. To quantify mean SNODAS bias at each of the coarser scales, we used intercept-only simple linear regression models of SNODAS bias. For both snow variables, we compared the estimated mean SNODAS bias and $95 \%$ CIs among scales, as well as SNODAS bias in snow shadows to other regions.

\section{RESUlts}

\section{SNODAS prediction accuracy and precision}

In total, we sampled 99 transects with 495 and 2475 measurements of SWE and snow depth, respectively, on 19 study sites. Of the 99 field estimates, we used 72 for our primary analyses (paired with 72 SNODAS predictions). The remaining 27 were repeated samples and only used for determining whether or not SNODAS bias increased through time. We did not see evidence of a temporal trend (Appendix A: Fig. A2), but it revealed 


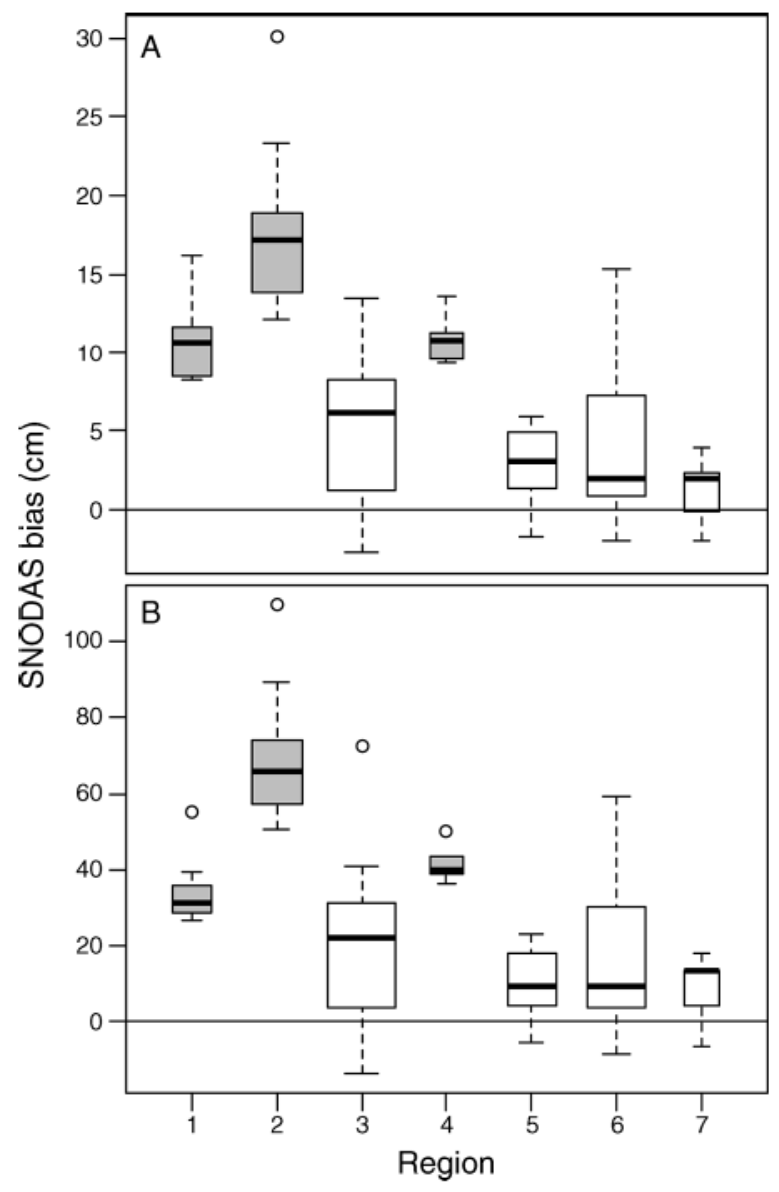

Fig. 2. Boxplots of Snow Data Assimilation System (SNODAS) bias (cm) for (A) SWE and (B) snow depth. SNODAS bias is the difference between SNODAS predictions and field estimates (transect means). Boxes identify quartiles and medians, whiskers are 1.5 times the interquartile range, and points outside of boxes identify minimum and maximum data points. Box widths are proportional to the number of observations within a region. Regions are ordered from northernmost (1) to southernmost (7). Gray boxplots are regions in the snow shadow on the lee side of a major mountain range.

spatial clustering of SNODAS bias for SWE by site that validated our use of random intercept models by site.

Snow conditions on each transect appeared to be similar to the general snow conditions of its study site (i.e., snow on a transect was not overly deep, shallow, or crusted compared to other locations while traveling across a study site). Field estimates of SWE ranged from 0.1 to $20 \mathrm{~cm}$, field estimates of snow depth ranged from 0.6 to $72.0 \mathrm{~cm}$, mean snow density was $21 \%$ (typical of mountain-continental snowpacks), and mean snow density by region ranged from $17.2 \%$ to $25.3 \%$. Estimated mean SNODAS bias varied within and among regions for both snow variables, but was greater in snow shadow regions (Fig. 2). Among regions, estimated mean SNODAS bias for SWE ranged from $1.2 \mathrm{~cm}(95 \% \mathrm{CI}=-6.7,9.1)$ to $17.3 \mathrm{~cm}(95 \% \mathrm{CI}=11.5$, $23.1)$ and for snow depth ranged from $8.5 \mathrm{~cm}(95 \% \mathrm{CI}=$
$-24.4,41.4)$ to $68.0 \mathrm{~cm}(95 \% \mathrm{CI}=44.1,91.9)$. Estimated mean SNODAS bias for SWE in snow shadow regions was $14.5 \mathrm{~cm}(95 \% \mathrm{CI}=10.8,18.2)$, compared to $4.1 \mathrm{~cm}$ $(95 \% \mathrm{CI}=2.1,6.0)$ in non-snow shadow regions. Estimated mean SNODAS bias for snow depth was $55.4 \mathrm{~cm}(95 \% \mathrm{CI}=39.6,71.1)$ in snow shadows, compared to $15.8 \mathrm{~cm}(95 \% \mathrm{CI}=7.6,24.0)$ in non-snow shadow regions.

Snow shadows also explained a portion of the relationship bias between SNODAS-predictions and field-estimates for both snow variables (Fig. 3). This relationship bias, in addition to the substantial scatter around the regression lines, resulted in wide $95 \%$ PIs for both snow variables. New SNODAS predictions of 0 $\mathrm{cm}, 10 \mathrm{~cm}$, and $20 \mathrm{~cm}$ corresponded to the following $95 \%$ PIs for SWE on the ground: $0-10 \mathrm{~cm}, 0-13 \mathrm{~cm}$, and 1-16 cm, respectively. For snow depth, new SNODAS predictions of $0 \mathrm{~cm}, 50 \mathrm{~cm}$, and $100 \mathrm{~cm}$ corresponded to $95 \%$ PIs of $0-46 \mathrm{~cm}, 0-58 \mathrm{~cm}$, and $0-71 \mathrm{~cm}$ snow depth on the ground, respectively. Prediction intervals were left-truncated at zero.

\section{Testing snow effects in an ecological model}

Using SNODAS predictions in place of field estimates resulted in a higher estimated probability of kill at $0 \mathrm{~cm}$ SWE ( 0.36 for SNODAS compared to 0.16 for field estimates of SWE), slower increase in the probability of kill with increasing SWE, and a lower estimated probability of kill at a mid-value $(15 \mathrm{~cm})$ of SWE ( 0.48 for SNODAS compared to 0.85 for field-estimated SWE; Fig. 4). The estimated slope on the logit scale using field estimates of SWE as the explanatory variable was 0.22 (95\% CIs $=0.09,0.35 ; P<0.001)$, compared to 0.03 (95\% CIs $=-0.03,0.10 ; P>0.3$ ) using SNODASpredicted SWE as the explanatory variable. These slope estimates correspond to a $24 \%$ increase in the relative odds an elk was killed by a predator for every $1 \mathrm{~cm}$ increase in field-estimated SWE, and a $3 \%$ increase in the relative odds an elk was killed for every $1 \mathrm{~cm}$ increase in SNODAS-predicted SWE.

\section{SNODAS prediction at multiple spatial scales}

Estimated SNODAS bias for both snow variables did not improve at broader spatial scales, and SNODAS bias was greater in snow shadows compared to other regions at all three spatial scales (Fig. 5). Estimated mean SNODAS bias for SWE was $6.9 \mathrm{~cm}(95 \% \mathrm{CI}=4.2$, 9.6) at the transect scale, $7.2 \mathrm{~cm}(95 \% \mathrm{CI}=-3.3,11.0)$ at the feedground scale, and $10.6 \mathrm{~cm}(95 \% \mathrm{CI}=2.9,18.3)$ at the region scale. Estimated mean SNODAS bias for snow depth was $26.4 \mathrm{~cm}(95 \% \mathrm{CI}=15.7,37.1)$ at the transect scale, $27.6 \mathrm{~cm}(95 \% \mathrm{CI}=12.9,42.4)$ at the feedground scale, and $39.1 \mathrm{~cm}(95 \% \mathrm{CI}=15.0,63.1)$ at the region scale.

\section{Discussion}

Model predictions of environmental variables are attractive as explanatory or predictor variables for 
logistical reasons, but these predictions carry uncertainty that can affect our conclusions about the relationships between environmental conditions and animal ecology. Our study compared field measurements of snow accumulation to SNODAS predictions to demonstrate the potential implications of ignoring model prediction uncertainty. We showed that SNODAS bias for SWE and snow depth was variable across all sampled transects and it was greatest in snow shadow regions (Figs. 2, 3, and 5). We did not anticipate that snow shadows would be a source of added prediction bias. Therefore, field measurements were necessary to identify and estimate the magnitude of this effect, though it appears common that model output are used as explanatory variables without studying the relationship between model predictions and field-measurements. The identification of snow shadows as one source of prediction bias suggests a potential for other local topographical or climate factors that could affect SNODAS prediction accuracy. Moreover, our identification of substantial bias across all regions is evidence that it is not appropriate to treat SNODAS predictions as data without error.

The high levels of SNODAS bias points to some of the general limitations of weather and climate models, including model structure and methods (e.g., algorithm, interpolation, downscaling), depiction of regional atmosphere-land fluxes and, in the case of relatively fine resolution snowpack models, depiction of local land surface properties that affect snow fall and accumulation (e.g., topography, vegetation, and water bodies [Wilby 1994, Wilby et al. 2004, Daly 2006, Fordham et al. 2011, Littell et al. 2011]). Though models are meant to be simple representations of complex processes, the exclusion of real-world details can result in prediction uncertainty, and we demonstrated through a simple simulation that this uncertainty can affect our understanding of the relationship between SWE and ecological processes, such as the probability that a predatory attack will succeed. For animals and contexts where snow effects may be strong, as is the case of large mammals in the Rocky Mountains, the inability to discern differences in individual or population-level responses to snow accumulation could impact species management or conservation efforts. For example, some Rocky Mountain elk populations face population declines or low calf recruitment (Creel et al. 2011), and effective management requires an understanding of how demographic rates are related to snow or other climaterelated factors, predation, and hunting. Beyond our analysis, similar impacts of prediction uncertainty on management and conservation are important to consider when projecting shifts in species distributions in response to climate change. Global circulation models are less accurate at describing local climates, and species distribution models may be sensitive to this uncertainty (Tabor and Williams 2010, Fordham et al. 2011, Winterhalter 2011).
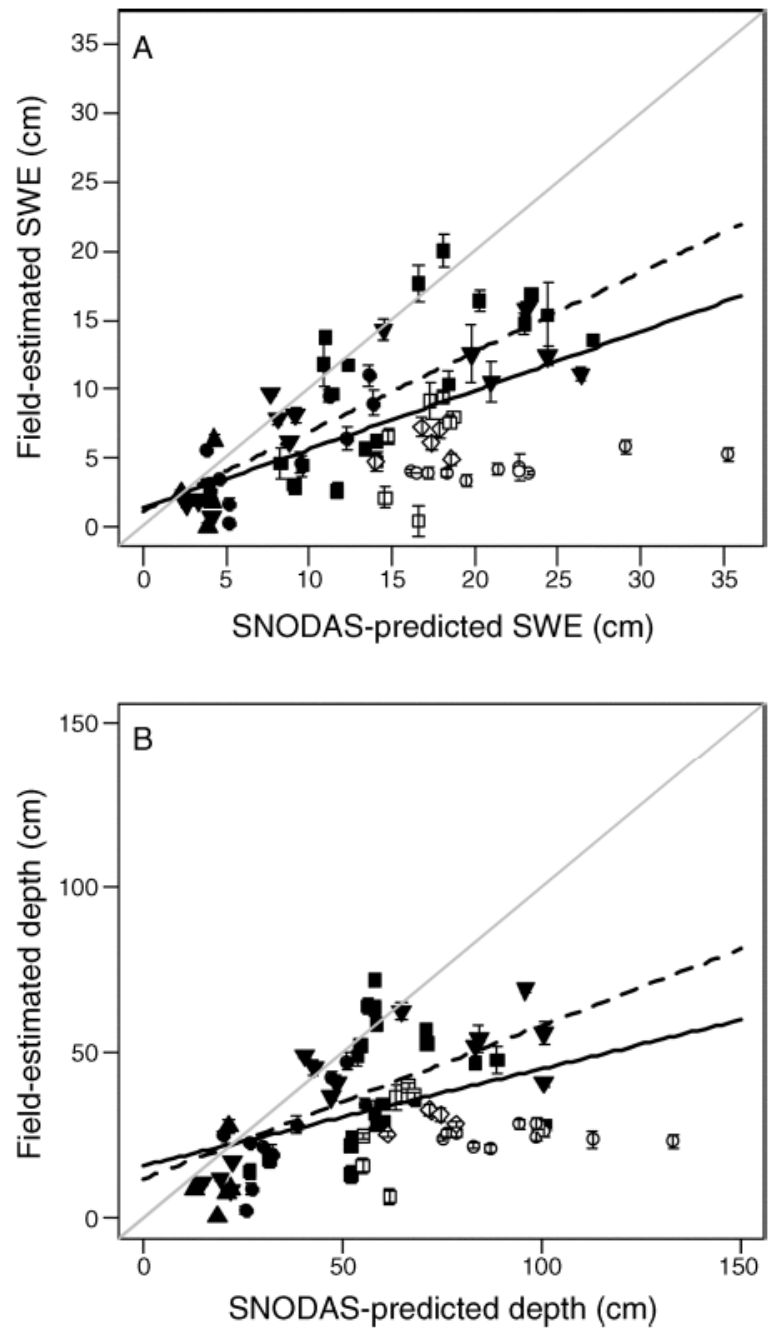

FIG. 3. Linear regressions of field estimates (transect means) on SNODAS predictions of (A) snow water equivalent (SWE; $\mathrm{cm}$ ) and (B) snow depth (cm) on elk feedgrounds and native winter ranges in western Wyoming. Different symbols indicate the seven regions of interest as depicted in Fig. 1; open symbols are regions located in a snow shadow. The solid black line is the estimated linear relationship across all transects sampled $(n=72$; SWE intercept $=1.37$ [95\% CIs $=-1.27,4.00]$, slope $=0.43[0.29,0.56]$; snow depth intercept $=15.98[4.51$, $27.45]$, slope $=0.29[0.14,0.45])$. The dashed black line is the estimated linear relationship across only non-snow shadow transects $(n=56$; SWE intercept $=1.17[-1.00,3.33]$, slope $=$ $0.58[0.44,0.72]$; snow depth intercept $=11.94[0.72,23.17$, slope $=0.46[0.28,0.64])$. Error bars are standard errors of the transect mean, and the gray line represents a 1:1 relationship between SNODAS predictions and field estimates. Linear models were mixed-effects models with site as random effect. Site refers to the 19 total study sites (16 feedgrounds plus 3 native winter ranges).

Depending on the scale of the question of interest, prediction uncertainty may have little effect on inferences. For example, averaging many predictions across large areas or timeframes for broad scale questions may be less biased than individual predictions used for fine scale questions, if the physical processes defined in the 

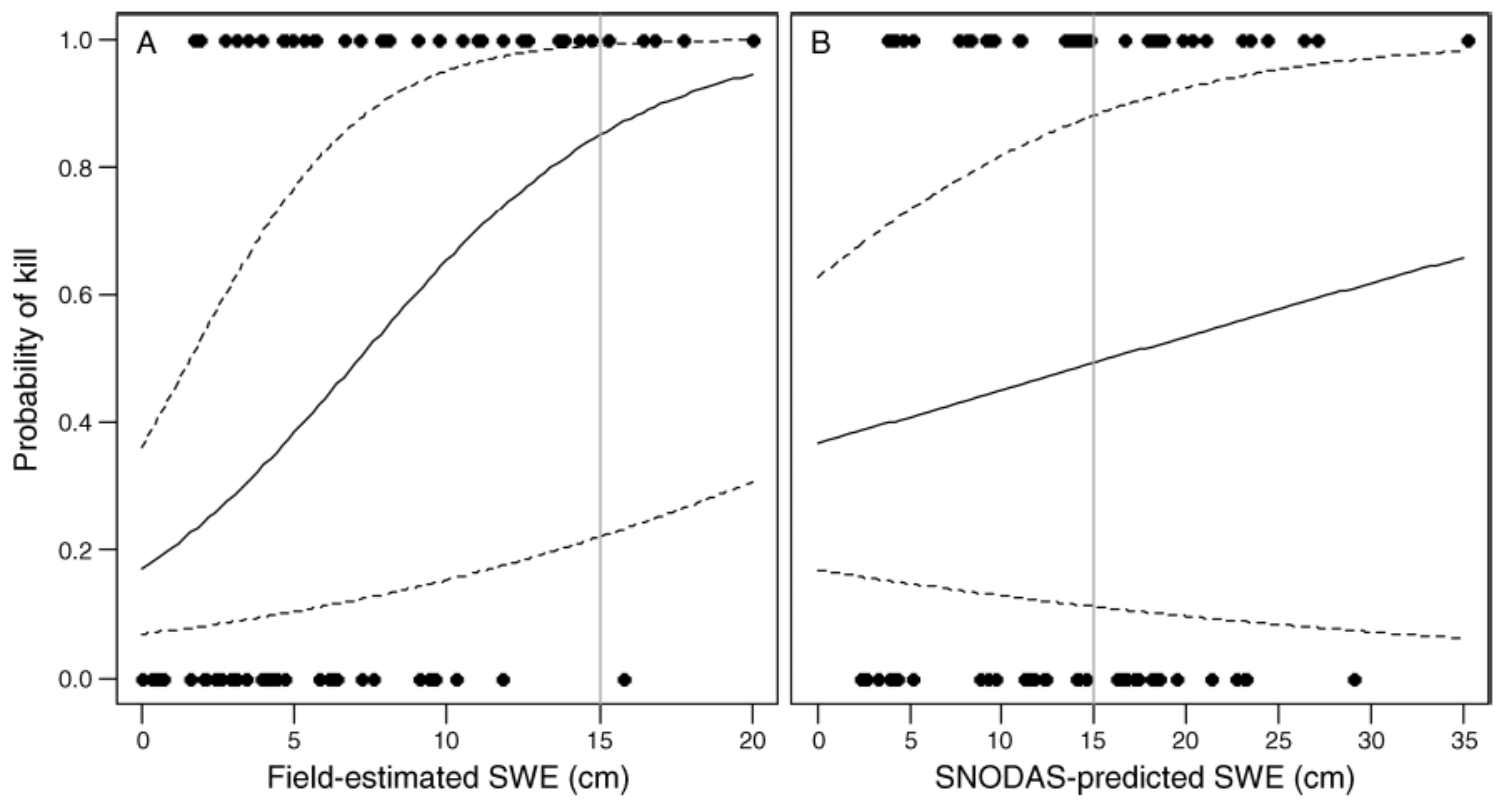

FIG. 4. The fitted logistic relationship (solid black lines) between the probability that an elk is killed by a predator and (A) field estimates of SWE $(\mathrm{cm})$ or (B) SNODAS-predicted SWE $(\mathrm{cm})$. Dashed black lines are $95 \%$ CIs, and gray lines identify estimated probability of kill and uncertainty at $15 \mathrm{~cm}$ SWE.

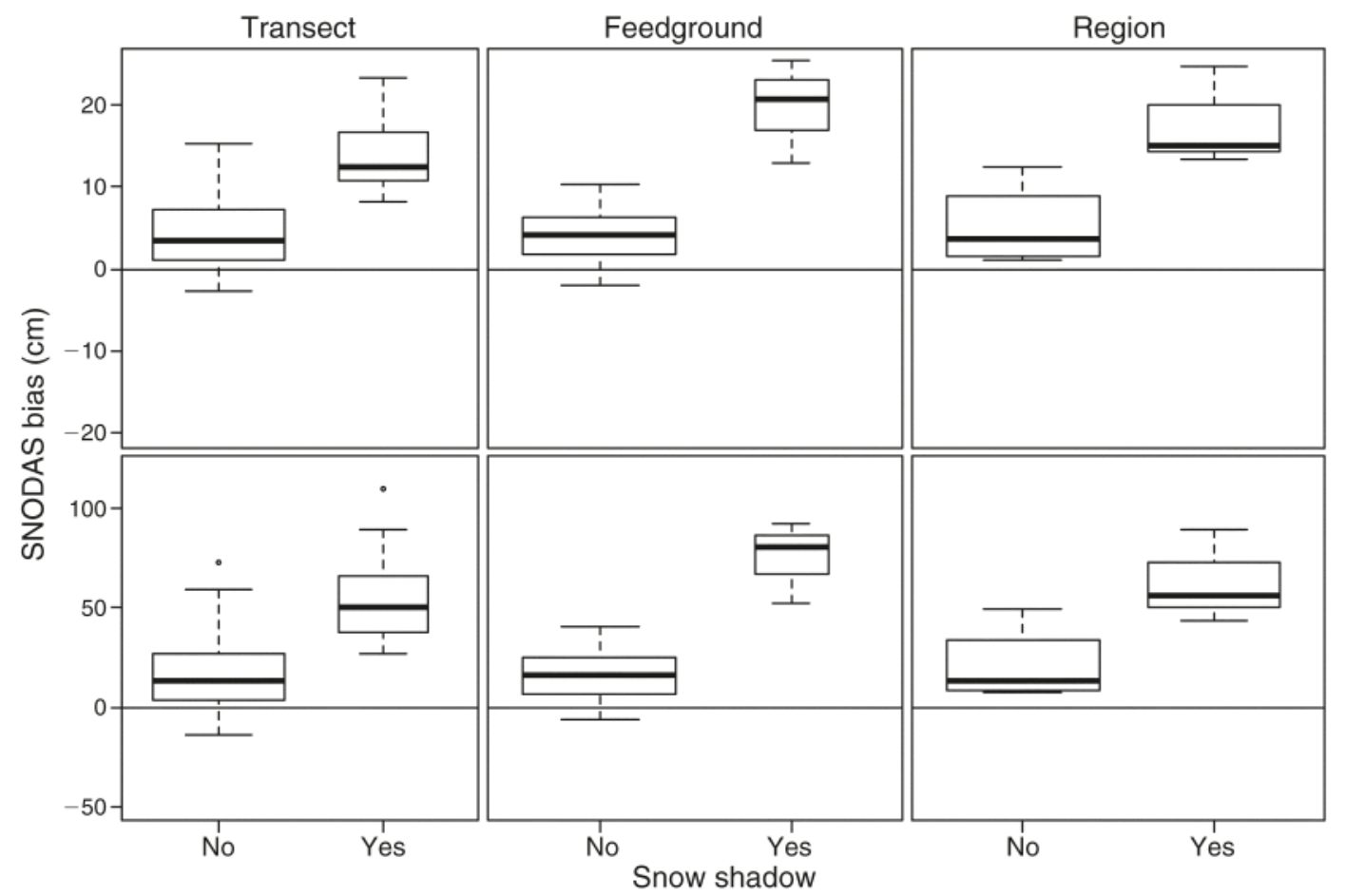

FIG. 5. Boxplots of SNODAS bias for SWE (top row) and snow depth (bottom row) at three spatial scales: transect (4500 $\mathrm{m}^{2}$; $n=72)$, feedground $\left(9-14 \mathrm{~km}^{2} ; n=16\right)$, and region $\left(150-2200 \mathrm{~km}^{2}, n=7\right)$. SNODAS bias is the difference between SNODAS predictions and field estimates (transect means). Grouping is by being located in a snow shadow (Yes) or not (No). Boxes identify quartiles and medians, whiskers are 1.5 times the interquartile range, and points outside of boxes identify minimum and maximum data points. Box widths are proportional to number of observations. 
model occur at coarser rather than finer scales. In other words, models may not capture fine scale variation because of few localized observations or a failure to account for important local physical processes (Wilby 1994, Wilby et al. 2004, Littell et al. 2011). In the case of SNODAS, it was developed for hydrologic modeling at basin-scales, not for applications at fine spatial or temporal scales relevant to individual animal behavior. Moreover, we were interested in how well SNODAS predicted snow at scales finer than the SNODAS pixel. Because SNODAS is not designed to account for withinpixel processes, it is understandable that SNODAS predictions did not match our field estimates, but this is a point often overlooked by ecologists looking for environmental data to explain fine scale ecological processes. Therefore, SNODAS, or models that make predictions at similar or coarser resolutions, may be better suited for broad scale studies applicable to large mammal populations. Though our study did not show decreases in estimated mean SNODAS bias at moderate scales $\left(9-14 \mathrm{~km}^{2}\right)$ or broad scales $\left(520-2200 \mathrm{~km}^{2}\right)$, a future study with larger sample sizes could reveal greater prediction accuracy at these coarser spatial scales.

Our study focused on SNODAS and identified areas where it poorly predicted snow accumulation, but the goal of our study was not to broadly condemn the use of SNODAS or other model predictions as covariates. Rather, we focused on estimating potential levels of prediction uncertainty and examining how this uncertainty can impact our understanding of how snow relates to elk ecology. Our linear regressions of field estimates on SNODAS predictions depicted bias when compared to a 1:1 relationship, and revealed a high degree of variability around the regression line (Fig. 3). Removal of snow shadows from these analyses decreased the relationship bias only slightly, and the scatter around the regression lines remained (Fig. 3). As a consequence of the bias and variability, new SNODAS predictions corresponded to a wide range of SWE and snow depth on the ground. It was also evident that SNODAS substantially over-predicts at higher values of field-estimated SWE and snow depth (Fig. 3).

As seen in our simulation, SNODAS prediction uncertainty could substantially affect inferences about the relationship between snow and animal ecology. Because field estimates of SWE were not excessively high (range of $0.1-20 \mathrm{~cm}$ was below the average SNOTEL SWE for 2009 and 2010 winters), the simulation more appropriately reflects responses in late-winter when elk physiological condition has been weakened (Becker 2008) to a point where even low to moderate snow levels could become important to survival. Strong responses of elk to snow, however, typically occur during more severe winters (Singer et al. 1997, Garrott et al. 2003). Because SNODAS tended to over-predict with substantial uncertainty at all levels of SWE and snow depth (Fig. 3), the importance of snow to elk ecology could be underestimated if using SNODAS in place of field measurements even during winters with above average snow accumulation.

Given the degree of variability among SNODAS predictions in our study, field measurements used as ground truth samples may not be enough to adjust SNODAS predictions to eliminate bias, though a thorough ground truth of SNODAS would include more transects or sample locations per pixel than was included in our study. Ground truth samples or reference data are often used to establish the relationship between model predictions (or remotely sensed observations) and field measurements, in order to remove bias from future model predictions (e.g., Czaplewski and Catts 1992). However, this process does not affect the scatter of individual predictions around the regression line. As this scatter increases, so does the prediction uncertainty, regardless of whether intensive ground-truth sampling occurred or not. Unless groundtruth sampling reveals greater precision among individual predictions than found in our study, SNODAS is probably better suited to monitoring trends over time or comparing among broad regions, rather than making comparisons among transects. Further study of SNODAS prediction uncertainty over broad areas and timeframes is needed to know if prediction uncertainty improves at these scales.

Our field estimates were transect means and therefore also had error associated with them. The difference between error in our field estimates vs. error in SNODAS predictions is our ability to quantify and model that error (Buonaccorsi 2010). With our sampling methods, for example, we were able to calculate standard errors of the mean, and these standard errors were very small relative to the difference between transect means and SNODAS predictions (Fig. 3). SNODAS or other model predictions, on the other hand, are provided without estimates of error and are often used as explanatory variables without acknowledging the potential for error and the effects it may have on inferences. However, in the case of GCMs where many models exist, the variability among model output can be quantified to understand potential prediction uncertainty (Fuentes et al. 2006, Tabor and Williams 2010, Fordham et al. 2011, Littell et al. 2011).

\section{CONCLUSIONS}

Prediction uncertainty from snowpack and climate models is expected because predictions are generated by interpolation between sparsely distributed direct observations or downscaling models that do not account for local physical processes. However, prediction uncertainty is rarely quantified or accounted for in studies of animal ecology that use model predictions in place of direct measurements. Blindly using model predictions as predictor variables without error can impact inferences, as we demonstrated in our example using SNODASpredicted SWE to explain the relative probability of an elk kill. While we only investigated SNODAS, the 
cautions with regard to inference are relevant when using other snowpack, weather or climate model predictions. Even the most sophisticated and highly regarded models are approximations, and the scale at which predictions are generated should not be ignored. Model predictions may be useful as indices for some questions of interest, but misleading when used at fine scales when prediction uncertainty is high.

\section{ACKNOWLeDGMENTS}

We thank J. Rogerson, J. Henningsen, E. Maichak, and A. Williams at the Wyoming Game and Fish Department for their assistance accessing study sites and sampling snow on elk winter range. We also thank A. Barbknecht for her hard work in collecting snow data. This work was supported by the National Science Foundation and National Institutes of Health Ecology of Infectious Disease (grant number DEB-1067129) and the United States Geological Survey. Any mention of trade, product, or firm names is for descriptive purposes only and does not imply endorsement by the U.S. Government.

\section{Literature Cited}

Anderson, D. P., J. D. Forester, M. G. Turner, J. L. Frair, E. H. Merrill, D. Fortin, J. S. Mao, and M. S. Boyce. 2005. Factors influencing female home range sizes in elk (Cervus elaphus) in North American landscapes. Landscape Ecology 20:257-271.

Barrett, A. 2003. National Operational Hydrologic Remote Sensing Center SNOw Data Assimilation System (SNODAS) products at NSIDC. NSIDC special report 11. Digital media. National Snow and Ice Data Center, Boulder, Colorado, USA.

Becker, M. S. 2008. Applying predator-prey theory to evaluate large mammal dynamics: wolf predation in a newlyestablished multiple-prey system. Dissertation. Montana State University, Bozeman, Montana, USA.

Beckmann, J. P., K. Murray, R. G. Seidler, and J. Berger. 2012. Human-mediated shifts in animal habitat use: sequential changes in pronghorn use of natural gas field in Greater Yellowstone. Biological Conservation 147:222-233.

Brodie, J. F., and E. Post. 2010. Nonlinear responses of wolverine populations to declining winter snowpack. Population Ecology 52:279-287.

Bruggeman, J. E. 2006. Spatio-temporal dynamics of the Central Bison Herd in Yellowstone National Park. Dissertation. Montana State University, Bozeman, Montana, USA.

Buonaccorsi, J. P. 2010. Measurement error: models, methods, and applications. Chapman and Hall/CRC, Boca Raton, Florida, USA.

Carroll, T., D. Cline, C. Olheiser, A. Rost, A. Nilsson, G. Fall, C. Bovitz, and L. Li. 2006. NOAA's national snow analyses. 74th Annual Meeting of the Western Snow Conference, Chanhassen, Minnesota, 2006. National Operational Hydrologic Remote Sensing Center, National Weather Service, NOAA, Chanhassen, Minnesota, USA.

Chaplot, V., A. Saleh, and D. B. Jaynes. 2005. Effect of accuracy of spatial rainfall information on modeling water, sediment, and $\mathrm{NO}_{3}-\mathrm{N}$ loads at the watershed level. Journal of Hydrology 312:223-234.

Christianson, D. A., and S. Creel. 2007. A review of environmental factors affecting winter elk diets. Journal of Wildlife Management 71:164-176.

Christianson, D., and S. Creel. 2008. Risk effects in elk: sexspecific responses in grazing and browsing due to predation risk from wolves. Behavioral Ecology 19:1258-1266.

Cord, A., and D. Rödder. 2011. Inclusion of habitat availability in species distribution models through multi-temporal remote-sensing data? Ecological Applications 21:3285-3298.
Craighead, J. J., F. C. Craighead, Jr., R. L. Ruff, and B. W. O'Gara. 1973. Home ranges and activity patterns of nonmigratory elk of the Madison Drainage Herd as determined by biotelemetry. Wildlife Monographs 33:3-50.

Creel, S., D. A. Christianson, and J. A. Winnie, Jr. 2011. A survey of the effects of wolf predation risk on pregnancy rates and calf recruitment in elk. Ecological Applications 21:28472853.

Czaplewski, R. L., and G. P. Catts. 1992. Calibration of remotely sensed proportion or area estimates for misclassification error. Remote Sensing of Environment 39:29-43.

Daly, C. 2006. Guidelines for assessing the suitability of spatial climate data sets. International Journal of Climatology 26:707-721.

Erb, L. P., C. Ray, and R. Guralnick. 2011. On the generality of a climate-mediated shift in the distribution of the American pika (Ochotona princeps). Ecology 92:1730-1735.

Farnes, P., C. Heydon, and K. Hansen. 1999. Snowpack distribution across Yellowstone National Park. Montana State University, Department of Earth Sciences, Bozeman, Montana, USA.

Farnes, P., and W. H. Romme. 1993. Estimating localized SWE on the Yellowstone Northern Range. Pages 59-66 in M. Ferrick and T. Pangburn, editors. Proceedings of the 50th Eastern Snow Conference and 61st Western Snow Conference, Quebec City, Canada.

Fordham, D. A., T. M. L. Wigley, and B. W. Brook. 2011. Multi-model climate projections for biodiversity risk assessments. Ecological Applications 21:3317-3331.

Fortin, D., M. E. Fortin, H. L. Beyer, T. Duchesne, S. Courant, and K. Dancose. 2009. Group-size mediated habitat selection and group fusion-fission dynamics of bison under predation risk. Ecology 90:2480-2490.

Franz, K. J., P. Butcher, and N. K. Ajami. 2010. Addressing snow model uncertainty for hydrologic prediction. Advances in Water Resources 33:820-832.

Fuentes, M., T. G. F. Kittel, and D. Nychka. 2006. Sensitivity of ecological models to their climate drivers: statistical ensembles for forcing. Ecological Applications 16:99-116.

Garrott, R. A., L. L. Eberhardt, P. J. White, and J. Rotella. 2003. Climate-induced variation in vital rates of an unharvested large-herbivore population. Canadian Journal of Zoology 81:33-46.

Hebblewhite, M., E. H. Merrill, and T. L. McDonald. 2005. Spatial decomposition of predation risk using resource selection functions: an example in a wolf-elk predator-prey system. Oikos 111:101-111.

Hobbs, N. T. 1989. Linking energy balance to survival in mule deer: development and test of a simulation model. Wildlife Monographs 101:3-39.

Hobbs, N. T., G. Wockner, F. J. Singer, G. Wang, L. Zeigenfuss, M. Coughenour, and S. Delgrosso. 2003. Assessing management alternatives for ungulates in the Greater Teton ecosystem using simulation modeling: final report. Natural Resource Ecology Lab, Colorado State University, Fort Collins, Colorado, USA.

Hoskinson, R. L., and J. R. Tester. 1980. Migration behavior of pronghorn in southeastern Idaho. Journal of Wildlife Management 44:132-144.

Huggard, D. J. 1993. Effect of snow depth on predation and scavenging by gray wolves. Journal of Wildlife Management 57:382-388.

Hupp, J. W., and C. E. Braun. 1989. Topographic distribution of sage grouse foraging in winter. Journal of Wildlife Management 53:823-829.

Kuczera, G., B. Renard, M. Thyer, and D. Kavetski. 2010. There are no hydrological monsters, just models and observations with large uncertainties! Hydrological Sciences Journal 55:980-991.

Littell, J. S., D. McKenzie, B. K. Kerns, S. Cushman, and C. G. Shaw. 2011. Managing uncertainty in climate-driven ecolog- 
ical models to inform adaption to climate change. Ecosphere 2:art102.

Maichak, E. J., B. M. Scurlock, J. D. Rogerson, L. L. Meadows, A. E. Barbknecht, W. H. Edwards, and P. C. Cross. 2009. Effects of management, behavior, and scavenging on risk of brucellosis transmission in elk of western Wyoming. Journal of Wildlife Diseases 45:398-410.

Nelson, M. E., and L. D. Mech. 1986. Relationship between snow depth and gray wolf predation on white-tailed deer. Journal of Wildlife Management 50:471-474.

Parker, K. L., C. T. Robbins, and T. A. Hanley. 1984. Energy expenditures for locomotion by mule deer and elk. Journal of Wildlife Management 48:474-488.

R Development Core Team. 2011. R: a language and environment for statistical computing. $\mathrm{R}$ Foundation for Statistical Computing, Vienna, Austria. http://www. R-project.org

Renard, B., D. Kavetski, E. Leblois, M. Thyer, G. Kuczera, and S. W. Franks. 2011. Towards a reliable decomposition of predictive uncertainty in hydrological modeling: characterizing rainfall errors using conditional simulation. Water Resources Research 47:W11516.

Rovansek, R. J., D. L. Kane, and L. D. Hinzman. 1993. Improving estimates of snowpack water equivalent using double sampling. Pages 157-164 in M. Ferrick and T. Pangburn, editors. Procedings of the 50th Eastern Snow Conference and 61st Western Snow Conference. Quebec City, Canada.

Singer, F. J., A. Harting, K. K. Symonds, and M. B. Coughenour. 1997. Density dependence, compensation, and environmental effects on elk calf mortality in Yellowstone National Park. Journal of Wildlife Management 61:12-25.

Sweeney, J. M., and J. R. Sweeney. 1984. Snow depths influencing winter movements of elk. Journal of Mammalogy 65:524-526.
Tabor, K., and J. W. Williams. 2010. Globally downscaled climate projections for assessing the conservation impacts of climate change. Ecological Applications 20:554-565.

Taper, M. L., and P. J. P. Gogan. 2002. The Northern Yellowstone elk: density dependence and climate conditions. Journal of Wildlife Management 66:106-122.

Telfer, E. S., and J. P. Kelsall. 1984. Adaptation of some large North American mammals for survival in snow. Ecology 65: $1828-1834$.

Watson, F. G. R., W. B. Newman, J. C. Coughlan, and R. A. Garrott. 2006. Testing a distributed snowpack simulation model against spatial observations. Journal of Hydrology 328:453-466.

Wilby, R. L. 1994. Stochastic weather type simulation for regional climate change impact assessment. Water Resources Research 30:3395-3403.

Wilby, R. L. 1997. Non-stationarity in daily precipitation series: implications for GCM downscaling using atmospheric circulation indices. International Journal of Climatology 17:439-54.

Wilby, R. L., S. P. Charles, E. Zorita, B. Timbal, P. Whetton, and L. O. Mearns. 2004. Guidelines for use of climate scenarios developed from statistical downscaling methods. Supporting material of the Intergovernmental Panel on Climate Change. http://unfocc.int/resource/cd_roms/na 1/v_and_a/Resource_ materials/Climate/StatisticalDownscalingGuidance.pdf

Wilby, R. L., and T. M. L. Wigley. 1997. Downscaling general circulation model output: a review or methods and limitations. Progress in Physical Geography 21:530-548.

Winterhalter, W. E. 2011. The accuracy of climate models' simulated season lengths and the effectiveness of grid scale correction factors. Ecological Applications 21:2313-2323.

Wyoming Game and Fish Department. 2006. 2005-2006 Annual feedground report. WGFD, Cheyenne, Wyoming, USA.

\section{Supplemental Material}

\section{Appendix}

Supplemental study site information, including the range of field-estimated snow water equivalent (SWE) and elevation in snow shadow vs. other regions, and the trend in SNODAS bias over time (Ecological Archives A023-030-A1). 